\title{
Fluorescence investigation of epoxy resin LG 285 and mathematical description of the curing process
}

\author{
Michaela Mikuličová*, Vladimír Vašek and Vojtěch Křesálek \\ Tomas Bata University in Zlin, Faculty of Applied Informatics, Nad Stranemi 4511, 76005 Zlin, Czech Republic
}

\begin{abstract}
In this paper, steady-state fluorescence spectroscopy is used to investigate the curing of twocomponent epoxy resin LG 285. Moreover, the process of curing is mathematically described. The mixture of resin and hardener HG 287 is measured at five different temperatures $\left(50{ }^{\circ} \mathrm{C}, 60{ }^{\circ} \mathrm{C}, 70{ }^{\circ} \mathrm{C}, 80{ }^{\circ} \mathrm{C}\right.$ and $90^{\circ} \mathrm{C}$ ) for five and a half hours. The results indicate that the process of curing of epoxy resin decelerates with time and accelerates with increasing temperature. Furthermore, the energy of the barrier is calculated.
\end{abstract}

\section{Introduction}

Epoxy resins are versatile polymers. These materials are flexible, very strong and have good electrical qualities; hence, epoxies are most commonly used as adhesives, binders, coatings and laminates [1-5]. This is the reason for their widespread expansion not only in the research area but also in practical application, especially in many industries. Epoxies are used for example in the automotive, aviation and shipping industry [2, 4], in electrotechnics $[1,2,6]$, in dentistry [7] and in optoelectronics [8]. An important property of the epoxies is their curing after application. For this purpose, hardeners are used. Hardeners are chemicals which react with epoxy groups to form a solid threedimensional network and to produce the required properties of the resin [2]. To improve the quality of the epoxies, nanoparticles [9-12] or dyes [8] can be added to the mixture. These additives change the properties of the resulting mixture according to the desired characteristics, which may be functional or aesthetic.

The process of curing of the resin is also fundamental for the quality of the resulting material $[5,13]$. To achieve the required properties, the curing must take place under the optimal conditions for the used material or mixture. The curing of epoxies can be investigated using various methods $[1-3,14]$. The most commonly used methods are, for instance, nuclear magnetic resonance, viscosity measurement, dielectric and Raman spectroscopy $[4,9,13]$.

The current research also focuses on the properties which depend on the composition of the epoxies. The spectroscopic methods NIR and MIR [14, 15] or UVVIS and FTIR [16] were used for this purpose. Epoxy/clay nanoparticles were investigated by X-ray diffraction, transmission electron microscopy, FTIR, UV-VIS and fluorescence [17]. Moreover, absorption and fluorescence were used to analyse the mechanochemical changes of epoxies to detect damage of the resin [18].

Research on resin degradation and ageing is of great importance. The effect of different chemical or electrical effects on the cured resin over time was examined using methods such as electroluminescence $[1,6,11]$ and chemiluminescence $[11,19]$. Spontaneous luminescence of heated cured samples, samples during the curing process and separate components (resin and hardener) were examined in [20].

This paper reports on the use of steady-state fluorescence spectroscopy for analysis of curing of epoxy resin and the mathematical description of the curing process at higher temperatures. Fluorescence spectroscopy is a rapid, simple and sensitive method for analysing organic and inorganic substances. Besides, this method is non-invasive, which means it does not alter the characteristics of the examined samples. For these reasons, fluorescence spectroscopy is widely used in many scientific disciplines such as chemistry, biochemistry, environmental chemistry, forensic analysis and food industry.

The advantage of using fluorescence spectroscopy to analyse the curing of epoxies is the simplicity of measurement and negligible influence on the process of curing or on the resin itself. Moreover, the measurement is contactless. The aim of this paper is to demonstrate the ability of steady-state fluorescence spectroscopy to investigate the curing of epoxy resin and to describe the curing process for higher temperatures mathematically.

\section{Experimental part}

\subsection{Instrumentation}

The curing of epoxy resin was investigated by steadystate fluorescence spectroscopy. Emission spectra were

* Corresponding author: mikulicova@utb.cz 


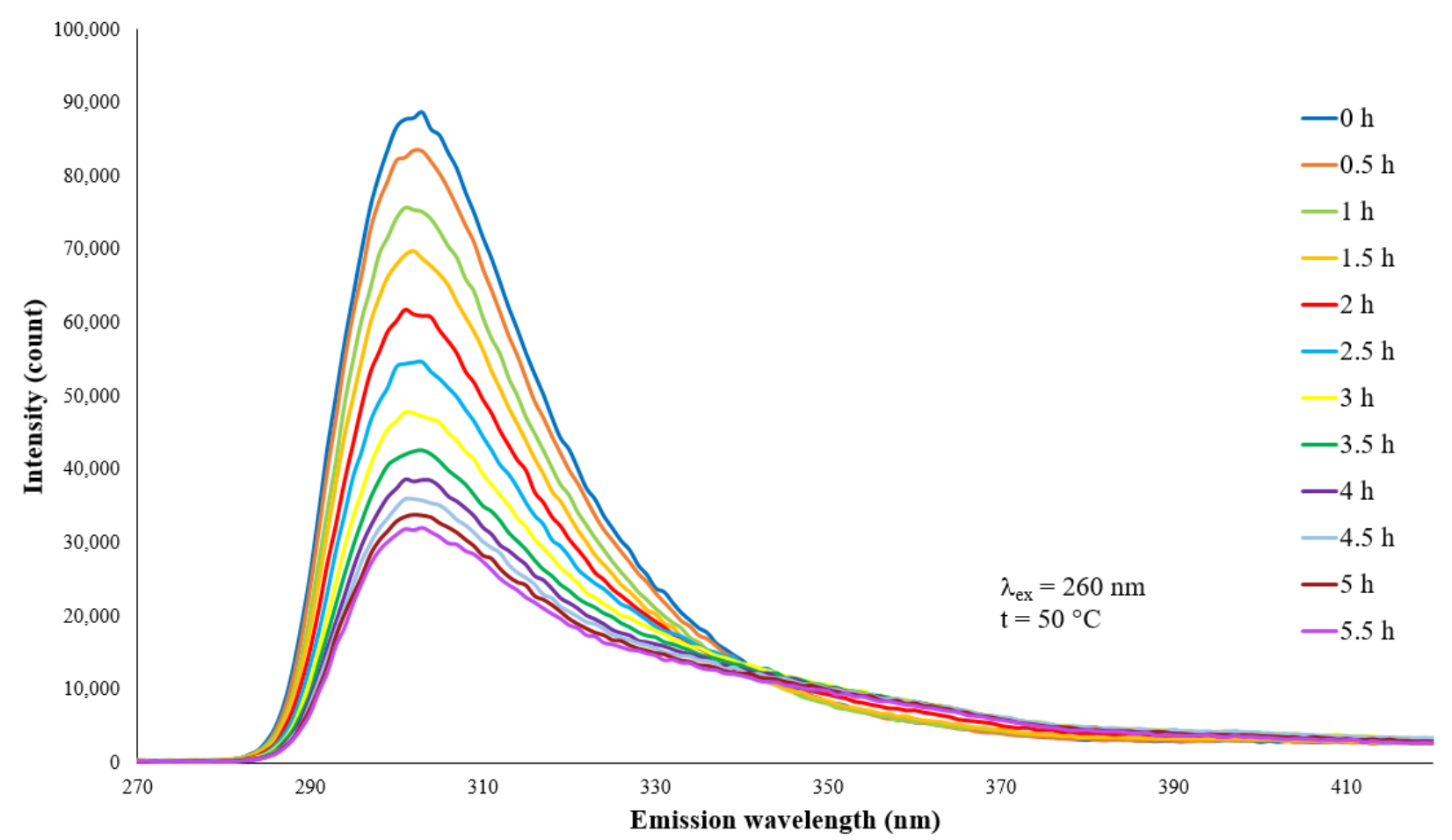

Fig. 1. Emission spectra of epoxy resin measured at the temperature of $50{ }^{\circ} \mathrm{C}$ for 5.5 hours.

obtained by an ISS PC1 spectrofluorometer. This instrument is equipped with $300 \mathrm{~W}$ high-pressure xenon arc lamp, which serves as a source of excitation light, and photomultiplier in photon counting mode, which serves as a highly sensitive detector. To measure in a horizontal plane, an optical fibre, pulled out of the instrument, was used. The fibre led an excitation light from the lamp to the sample. Moreover, it led a fluorescence emitted by the sample to the photomultiplier. After a series of experiments, an optimal excitation wavelength was set to $260 \mathrm{~nm}$. The emission spectra were measured in the range from 270 to $420 \mathrm{~nm}$.

\subsection{Samples}

The two-component lamination resin LG 285 was investigated. This epoxy resin is used especially for the manufacture of composite parts of aircraft and ships. The resin LG 285 was mixed with low-viscosity hardener HG 287 in a ratio of 100:40. The thin layer of the resulting mixture was measured every 30 minutes for five and a half hours. The measurements were performed for samples cured at temperatures of $50^{\circ} \mathrm{C}, 60^{\circ} \mathrm{C}, 70^{\circ} \mathrm{C}, 80$ ${ }^{\circ} \mathrm{C}$ and $90{ }^{\circ} \mathrm{C}$.

\section{Results}

The aim of the experiment was to show the ability of steady-state fluorescence spectroscopy to investigate the curing of epoxy resin and mathematically describe the process of curing for higher temperatures. For this purpose, the mixture of epoxy resin LG 285 and hardener HG 287 was analysed.
Figure 1 shows the emission spectra of resin measured at a temperature of $50{ }^{\circ} \mathrm{C}$ for five and a half hours. As can be seen, the intensity of fluorescence decreased gradually. This indicates that the process of curing of epoxy resin decelerates with time for higher temperatures. The emission spectra of resin measured at temperatures of $60{ }^{\circ} \mathrm{C}, 70{ }^{\circ} \mathrm{C}, 80{ }^{\circ} \mathrm{C}$ and $90{ }^{\circ} \mathrm{C}$ were obtained in the same way.

To analyse the velocity of curing, the most significant peak at $302 \mathrm{~nm}$ was chosen for further analysis. The intensity in time $t=0 \mathrm{~h}$ was marked as $I_{0}$, the intensities measured during the process of curing were marked as $I_{t}$. The change of fluorescence intensity over time can be described by equation (1):

$$
d I=-I k(t) d t, \text { where } k(t)=k_{0} e^{-b t}
$$

Subsequently, the equation is integrated and adjusted:

$$
\begin{aligned}
& \int_{I(0)\}}^{I\left[t^{2}\right)} \frac{d I}{I}=\int_{0}^{t}-k_{0} e^{-b t} d t \\
& \ln \frac{\pi(0)}{t(t)}=\frac{k_{0}}{b}\left[1-e^{-b t}\right] \\
& \lim _{t \rightarrow \infty}\left(\ln \frac{\pi(0)}{R(t)}\right)=\frac{k_{0}}{b} \\
& \ln \frac{d(0))}{U(t)}=\frac{k_{0}}{b}\left[1-\left(1-b t+\frac{1}{2} b^{2} t^{2}-\cdots\right)\right] \\
& \ln \frac{\pi(0)}{d(t))}=k_{0} t-\frac{1}{2} k_{0} b t^{2}+\cdots
\end{aligned}
$$

All intensities were converted into the logarithm of the ratio of intensity $I_{0}$ to intensity $I_{t}$, according to equation (6). Time dependencies of these converted intensities are illustrated in Figure 2. As can be seen, the process of curing of epoxy resin accelerates with increasing temperature. Time dependencies of the 


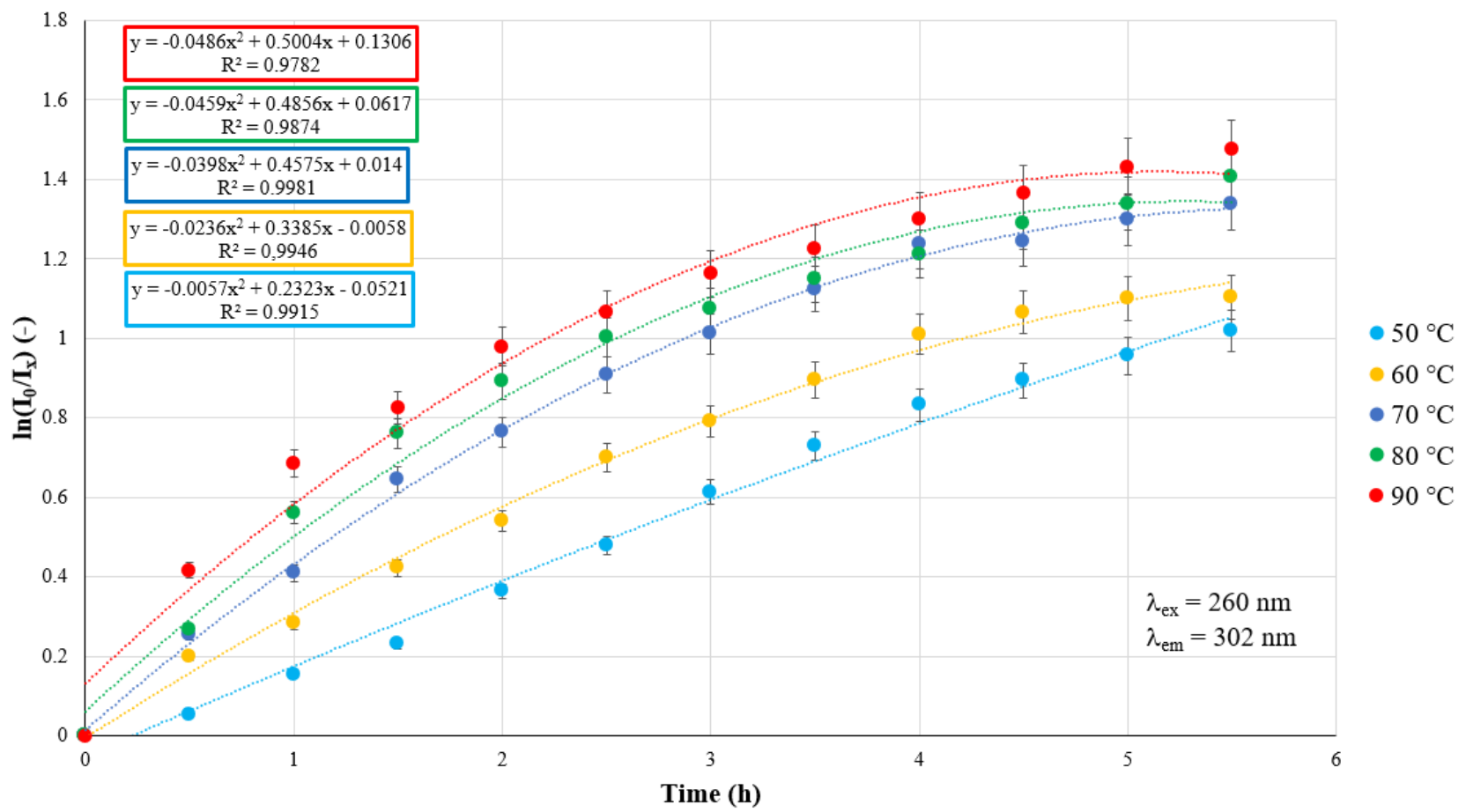

Fig. 2. Time dependencies of the logarithm of fluorescence intensity ratio for individual curing temperatures and their polynomial functions.

logarithm of fluorescence intensity ratio are characterized by appropriate polynomial functions which correspond to the temperatures. Linear polynomials of these functions are called rate constant $k_{0}$ of the ongoing reaction.

Besides, a modified Arrhenius equation (7) was used to describe fluorescence behaviour. In the equation, $w_{0}$ is the energy of barrier which the molecule must overcome to enter the crosslinking reaction, $k_{B}$ is the Boltzmann constant and $T$ is the thermodynamic temperature. For example, the product of $k_{B} T$ is approximately $25 \mathrm{meV}$ at a temperature of $293.15 \mathrm{~K}\left(20^{\circ} \mathrm{C}\right)$.

$$
\begin{aligned}
k_{0} & =A e^{-w_{0} d_{k_{B} T}} \\
\ln k_{0} & =\ln A-\frac{w_{0}}{k_{g}} \times \frac{1}{T}
\end{aligned}
$$

The dependency of the logarithm of rate constant $k_{0}$ on the reciprocal value of thermodynamic temperature $T$ from the equation (8) is presented in Figure 3. 


\section{$\mathbf{1} / \mathbf{T}\left(\mathbf{K}^{-1}\right)$}

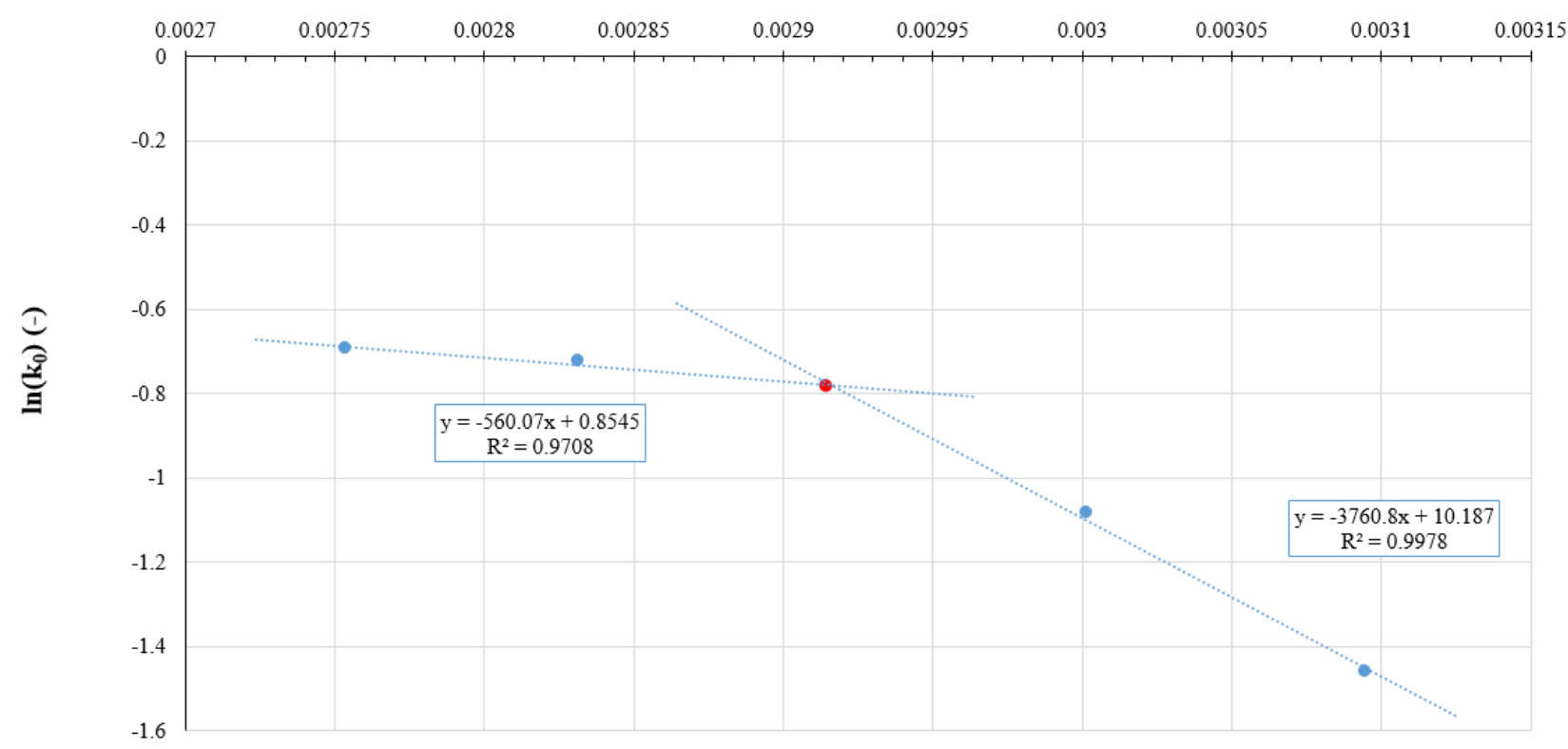

Fig. 3. Dependency of logarithm of rate constant $k_{0}$ on reciprocal value of thermodynamic temperature $T$.

As can be seen, two linear trendlines were fitted to the data. These trendlines represent two different processes of curing: one for temperatures in the range from $323.15 \mathrm{~K}\left(50{ }^{\circ} \mathrm{C}\right)$ to $343.15 \mathrm{~K}\left(70{ }^{\circ} \mathrm{C}\right)$ and one for temperatures in the range from $343.15 \mathrm{~K}\left(70{ }^{\circ} \mathrm{C}\right)$ to $363.15 \mathrm{~K}\left(90^{\circ} \mathrm{C}\right)$. This indicates that the behaviour of investigated epoxy resin varies for higher and lower temperatures; however, further research is required to determine and characterize the cause of this change in resin behaviour.

In addition, the energy of barrier $w_{0}$ for these two processes can be calculated from polynomial functions in Figure 3. These polynomial functions correspond to equation (8). The energy of barrier w0 is $324 \mathrm{meV}$ for temperatures in the range from $323.15 \mathrm{~K}\left(50{ }^{\circ} \mathrm{C}\right)$ to $343.15 \mathrm{~K}\left(70^{\circ} \mathrm{C}\right)$ and $48 \mathrm{meV}$ for temperatures in the range from $343.15 \mathrm{~K}\left(70^{\circ} \mathrm{C}\right)$ to $363.15 \mathrm{~K}\left(90^{\circ}\right)$. As can be seen, the energy of barrier $w_{0}$ decreases with increasing temperature. This means that the process of curing is faster for higher temperatures because molecules can easier enter the crosslinking reaction.

\section{Conclusion}

Steady-state fluorescence spectroscopy was used to investigate the curing of epoxy resin LG 285 mixed with hardener HG 287. Moreover, the process of curing was mathematically described. The given results indicate that the process of curing of epoxy resin decelerates with time and accelerates with increasing temperature. Furthermore, it was found that there are two different processes of curing: one for one for temperatures in the range from $323.15 \mathrm{~K}\left(50{ }^{\circ} \mathrm{C}\right)$ to $343.15 \mathrm{~K}\left(70{ }^{\circ} \mathrm{C}\right)$ and one for temperatures in the range from $343.15 \mathrm{~K}\left(70{ }^{\circ} \mathrm{C}\right)$ to $363.15 \mathrm{~K}\left(90^{\circ} \mathrm{C}\right)$. The measured data were processed to calculate the energy of barrier w0 for these two processes. It was found that the energy of barrier decreases with increasing temperature.

Although fluorescence spectroscopy provides no information about resin compounds which have no fluorescence properties, this method can be recommended to investigate the process of curing. The great advantage is that the measurement is rapid and contactless. One of the challenges for future research is to extend the given mathematical description of the curing process.

This work was supported by the Internal Grant Agency of Tomas Bata University under the project No. IGA/FAI/2019/003.

\section{References}

[1] O. Gallot-lavallée, G. Teyssedre, C. Laurent, S. Rowe, Polymer, 46, 2722 (2005)

[2] M. Janošová, Vytvrzování epoxidových systémů, (Dipl., FT UTB, 2011)

[3] J. Lange, R. Ekelöf, G.A. George, Polymer, 40, 149 (1999)

[4] R.E. Lyon, K.E. Chike, S.M. Angel, J. Appl. Polymer Sci., 53, 1805 (1994)

[5] G.J. Sewell, N.C. Billingham, K.A. Kozielski, G.A. George, Polymer, 41, 2113 (2000)

[6] V. Griseri, L.A. Dissado, J.C. Fothergill, C. Laurent, G. Teyssèdre, J. Ph. D: Appl. Ph., 34, 2534 (2001)

[7] A. Ivanisevic, T. Lainovic, L. Blazic, M. Vilotic, Proc. Eng., 69, 921 (2014)

[8] A. Eronen, A. Harju, J. Mutanen, H. Lajunen, M. Suvanto, T. Pakkanen, M. Kuittinen, Opt. Ex., 23, 33419 (2015) 
[9] L.S. Cividanes, D.D. Brunelli, E.F. Antunes, E.J. Corat, K.K. Sakane, G.P. Thim, J. Appl. Polymer Sci., 130, 544 (2013)

[10] L.S. Cividanes, E.A.N. Simonetti, M.B. Moraes, F.W. Fernandes, G.P. Thim, Polymer Eng. Sci., 54, 2461 (2014)

[11] W. Guo, A. Zhang, X. Zhang, Ch. Huang, D., Yang, N. Jia, Anal. Bioanal. Chem. 408, 7173 (2016)

[12] I. Ropus, G. Carcia, M. Giorcelli, A. Tagliaferro, T. Haramina, L. Curkovic, Proceedings of the 26th DAAAM International Symposium, 0940 (2016)

[13] M. Younes, S. Wartewig, D. Lellinger, B. Strehmel, V. Strehmel, Polymer, 35, 5269 (1994)

[14] N. Poisson, G. Lachenal, H. Sautereau, Vib. Spectros, 12, 237 (1996)

[15] A. Rigail-Cedeño, Ch.S.P. Sung, Polymer, 46, 9378 (2005)

[16] Y.E. Xu, Ch.S.P. Sung, Macromolecules, 35, 9044 (2002)

[17] M. Mondragón, M.A. Cortes, E. Arias, C. Falcony, O. Zelaya-Angel, Polymer Eng. Sci., 51, 1808 (2011)

[18] R. Toivola, S. Jang, D. Mannikko, S. Stoll, A. K.Y. Jen, B.D. Flinn, Polymer, 142, 132 (2018)

[19] T. Suzuki, T. Sunose, I. Amasaki, T. Ozawa, Polymer Deg. Stab., 77, 87 (2002)

[20] O. Gallot-lavallée, G. Teyssedre, C. Laurent, S. Robiani, S. Rowe, J. Appl. Polymer Sci., 100, 1899 (2006) 